\title{
Bons na economia e bons na transparência? Estudo da correlação entre indicadores econômicos e de transparência nos estados brasileiros
}

Temática cada vez mais discutida no âmbito da administração pública, a transparência pode enriquecer a qualidade da democracia, melhorar a accountability, possibilitar uma maior inserção social e diminuir a corrupção. Assim, refletir sobre a efetividade da transparência reportada pelos entes da federação e os elementos que podem fundamentá-la torna-se cada vez mais relevante. Nesse contexto, este trabalho teve por objetivo verificar se há correlação entre índices nacionais de transparência divulgados pelos órgãos de controle (Controladoria Geral da União - CGU e Ministério Público Federal - MPF) e indicadores econômicos (dos estados brasileiros). Para consecução do estudo, foi feita análise de regressão entre os indicadores citados (transparência e econômicos), com o intuito de verificar se esses explicam aqueles. Adicionalmente, foi feito o teste de correlação dos coeficientes por ordem Spearman com o intuito de ratificar os achados da regressão. Os resultados mostram que os indicadores econômicos (DTP/RCL e DCL/RCL) não explicam os indicadores de transparência apresentados pelos estados (Índice Nacional de Transparência - INT-MPF e o Índice Escala Brasil Transparente- EBT-CGU), visto que os modelos de regressão aplicados não são significativos. Os testes de correlação por ordem de Spearman ratificaram os resultados obtidos. Portanto, não há indícios de que as variáveis estejam correlacionadas.

\section{Good on the economy and good on transparency? Study of the correlation between economic and transparency indicators in Brazilian states}

\begin{abstract}
Increasingly discussed in public administration, transparency can enrich the quality of democracy, improve accountability, enable greater social inclusion and decrease corruption. Thus, reflecting on the effectiveness of transparency reported by the federation entities and the elements that can substantiate it becomes increasingly relevant. In this context, this study aimed to verify if there is a correlation between national indexes of transparency disclosed by the control agencies (Comptroller General of the Union - CGU and Federal Prosecutor - MPF) and economic indicators (of Brazilian states). To achieve the study, a regression analysis was performed between the cited indicators (transparency and economic), in order to verify if they explain those. Additionally, the Spearman correlation coefficient test was performed to ratify the regression findings. The results show that the economic indicators (DTP / RCL and DCL / RCL) do not explain the transparency indicators presented by the states (National Transparency Index - INT-MPF and the Brazil Transparent Scale Index - EBT-CGU), since the models of regression applied are not significant. Spearman's order correlation tests ratified the results obtained. Therefore, there is no evidence that the variables are correlated.
\end{abstract}

Keywords: Public administration; Transparency; Transparency indices; Fiscal management indicators; Correlation.

Topic: Gestão Pública

Reviewed anonymously in the process of blind peer.
Received: 07/06/2018

Approved: $10 / 08 / 2018$
Elyrouse Cavalcante de Oliveira Bellini Universidade Federal de Pernambuco, Brasil http://lattes.cnpq.br/2523512608621919 elyrouse@gmail.com

Alexandre César Batista da Silva

Universidade Federal de Pernambuco, Brasil http://lattes.cnpq.br/4167579847277378 acbspe@uol.com.br

Juliene Gama Tenório

Universidade Federal de Pernambuco, Brasil http://lattes.cnpq.br/4635058462726912 julienetenorio@hotmail.com

DOI: 10.6008/CBPC2179-684X.2018.002.0009
Maurício Assuero Lima de Freitas

Universidade Federal de Pernambuco, Brasil

http://lattes.cnpq.br/6395847929002275

massuero@ig.com.br

Luiz Carlos Miranda

Universidade Federal de Pernambuco, Brasi

http://lattes.cnpq.br/8204968147626364

mirandaphd@gmail.com
Referencing this:

BELLINI, E. C. O.; SILVA, A. C. B.; TENÓRIO, J. G.; FREITAS, M. A. L.; MIRANDA, L. C.. Bons na economia e bons na transparência? Estudo da correlação entre indicadores econômicos e de transparência nos estados brasileiros. Revista Brasileira de Administração Científica, v.9, n.2, p.118-134, 2018. DOI: http://doi.org/10.6008/CBPC2179684X.2018.002.0009 


\section{INTRODUÇÃO}

No intuito de cumprir com suas funções institucionais, voluntariamente ou por imperativo legal, a administração pública tem buscado se utilizar cada vez mais da eficiência, eficácia, efetividade e economicidade na gestão dos recursos públicos. Além disso, há maior participação da sociedade no processo decisório e no controle dos serviços públicos (OSBORNE et al., 1995). Nesse contexto, avaliar a transparência das informações disponibilizadas pelo poder público é premissa fundamental para o amadurecimento das democracias, entretanto, as pesquisas demonstram baixa divulgação de informações da administração pública para a sociedade, apesar da vigência da Lei Complementar no 101/2000, que tem sido considerada, nos últimos anos, como possível solução para problemas como desequilíbrio fiscal, aumento da dívida pública e corrupção, além de contribuir na busca da governança no setor público (RIBEIRO et al., 2012).

A LRF/2000, alicerçada em quatro eixos (planejamento, controle, responsabilização e transparência), regulamentou, entre outros, o artigo 163 da Contribuição Federal de 1988 (CF/1988, caput e dos incisos I ao IV) e criou padrões de responsabilidade na gestão das contas públicas por meio de instrumentos de transparência fiscal (SANTANA JÚNIOR, 2008). A transparência e o acesso à informação estão previstos como direito do cidadão e dever do Estado na CF/1988 e em outros normativos, como a LRF/2000; a Lei Complementar no 131/2009 (Lei da Transparência), regulamentada pelo Decreto no 7.185/2010 e, mais recentemente, a Lei no 12.527/2011 (Lei de Acesso à Informação - LAI), regulamentada pelo Decreto no 7.724/2012; além dos guias de implantação elaborados pela Controladoria Geral da União, alterados pelo Decreto no 8.408, de 24 de fevereiro de 2015.

O Fundo Monetário Internacional (FMI) realizou uma pesquisa a qual evidencia que a existência ou ausência do controle social diferenciava países em desenvolvimento efetivo de países em crises recorrentes. Nos países onde a sociedade demanda, participa, cobra, acompanha, fiscaliza e avalia os resultados da gestão pública, os governos fazem bons orçamentos e onde a sociedade não tem essa atuação, os governos praticam orçamentos de má qualidade. $O$ estudo também identificou que o motivo para alguns países democráticos não realizarem o controle social é a ausência de "transparência fiscal" (SHEFFER, 2007).

Sob a ótica desta conjuntura apresentada, percebe-se que há um empenho legislativo para que as informações da gestão pública sejam divulgadas de forma mais efetiva, um exemplo disso foi a criação da Lei de Acesso à Informação, que tem tido uma maior participação e pressão social para que ocorra o seu cumprimento. Porém, deve-se atentar ao fato de que a obrigatoriedade de divulgação de informações não significa a transparência dos atos dos gestores públicos, existindo uma diferença conceitual entre publicidade e transparência fiscal (RIBEIRO et al., 2012). A publicidade fiscal é tornar públicas 'informações' do ponto de vista de quem fornece, e não de quem recebe. E transparência fiscal é disponibilizar as informações que fazem sentido para o público-alvo, no caso, para os cidadãos (SCHEFFER, 2007).

Assim, de acordo com o que foi exposto, percebe-se a importância da disclosure nas Organizações e Entidades Públicas, não devendo confundi-la "com a informação em si, pois seu sentido é mais abrangente, podendo ser definido com a divulgação de informações contábeis comunicada pela empresa que tem o objetivo de dar informações úteis a seus clientes, tornando-as públicas" (FIPECAFI, 2012). Portanto, seu 
conceito está relacionado diretamente à transparência corporativa e, quanto melhor for a disclosure, mais transparente é a instituição. Diante do exposto, buscando contribuir com estudos para o desenvolvimento da eficácia e eficiência da gestão pública e com o aperfeiçoamento das relações entre cidadãos e governo, pretende-se com esta pesquisa responder a seguinte questão orientadora: que influências exercem indicadores econômicos nos índices de transparência dos estados brasileiros divulgados pelos órgãos de controle Controladoria Geral da União (CGU) e Ministério Público Federal (MPF)?.

Em consonância com a questão constituída, o objetivo geral desse estudo é analisar se indicadores econômicos exercem influências sobre os índices de transparência dos estados brasileiros divulgados pelos órgãos de controle (CGU/MPF), analisando, especificamente, os marcos conceituais referentes à Transparência Fiscal atrelados ao uso dos testes de correlação e de modelos de regressão linear aplicados sobre os indicadores pertinentes.

Tem-se os seguintes objetivos específicos: Identificar, na legislação e na literatura especializada, os marcos conceituais referentes à Transparência Fiscal, a Lei de Acesso à informação e Indicadores Econômicos para dar sustentação ao delineamento da investigação pretendida; Demonstrar a metodologia adotada para a elaboração dos Índices de Transparência Nacionais da CGU e do MPF; Analisar se há correlação entre os Índices de Transparência Nacionais da CGU e do MPF com indicadores econômicos, mais notadamente Despesa Total de Pessoal (DTP)/Receita Corrente Líquida (RCL) e Dívida Consolidada Líquida (DCL) /Receita Corrente Líquida (RCL), referentes ao último quadrimestre de 2015.

A transparência tem sido um tema cada vez mais debatido nas discussões sobre organizações públicas, sendo considerada indispensável para o aumento na qualidade da democracia, à medida que favorece a accountability, a participação social e a diminuição da corrupção (NERY, 2014; GAVELIN et al., 2009). “Hoje faz-se necessária mais do que uma discussão sobre a relevância da Transparência nas Administrações Públicas, mas uma avaliação da eficácia das ações que estão sendo tomadas" (NERY, 2014).

Vários trabalhos apresentam fundamentos teóricos e práticos sobre a moderna administração pública, voltada para resultados, eficiência, eficácia, efetividade, responsabilidade, prestação de contas e, já sendo cobrada há algum tempo pela sociedade, a transparência. Nesse contexto, a necessidade da reflexão sobre a efetividade da Transparência Fiscal pelos entes da federação torna-se cada vez mais relevante.

Adicionalmente, alguns autores publicaram estudos demonstrando uma correlação positiva entre transparência e índices econômicos sociais. Santana Júnior (2008), objetivando analisar os níveis de transparência fiscal eletrônica nos sites dos governos e Órgãos estaduais e sua associação com indicadores econômico-sociais, com base nos novos padrões de responsabilidade na gestão das contas públicas impostos pela LRF, evidenciou em seus resultados, em média, uma baixa aderência à integralidade das exigências legais de transparência fiscal eletrônica nos sites dos entes examinados.

Entretanto, foram analisadas, por meio de teste estatístico não-paramétrico de Correlação de Spearman, a associação entre a variável representativa dos níveis de transparência fiscal eletrônica do órgão/poder, cujos resultados levaram a conclusão de que há associação entre os indicadores econômicos 
sociais e os níveis de transparência fiscal eletrônica observados nos sites, com exceção do Ministério Público que não apresentou associação.

Cruz et al. (2009) verificou a possibilidade de existência de relação entre o Índice de transparência fiscal eletrônica e alguns indicadores sociais e econômicos dos maiores municípios do Estado do Rio de Janeiro, bem como os fatores que, possivelmente, influenciam a evidenciação e a transparência de informações relativas à gestão fiscal (população, receita orçamentária, PIB per capita, taxa de alfabetização, IDH-M, IQM e estágio do site). Por intermédio das análises realizadas, pôde-se concluir que existe associação entre os indicadores sociais e econômicos e os níveis de transparência fiscais eletrônicos observados nos sites dos maiores municípios do Estado do Rio de Janeiro, com exceção das variáveis população e PIB per capita, que não apresentaram significância estatística.

Diante de tudo o que foi exposto, e tendo a LRF como um dos seus objetivos combater os desvios de finalidade das verbas públicas, dispondo sobre preceitos de conduta que estabelecem regras e limites para os administradores públicos aplicarem com responsabilidade os recursos da sociedade, visando o planejamento, a responsabilização, o controle e a transparência, esse trabalho justifica-se à medida que busca contribuir com a sociedade, academia e governo, com estudos sobre o grau de Transparência, especialmente em Portais de Transparência governamentais e sua possível associação com indicadores econômicos.

\section{REVISÃO TEÓRICA}

\section{Transparência fiscal}

Transparência, segundo Slomski (2005), é a divulgação oportuna de todas as questões relevantes relacionadas à organização, incluindo situação financeira, desempenho, composição e governança. De um modo geral, a transparência deve contemplar todas as atividades realizadas pelos gestores públicos, dando acesso e compreensão a todos os cidadãos do que eles têm realizado por meio do poder de representação que Ihes foi confiado. Nesse sentido, transparência fiscal pode ser entendida como a possibilidade do acompanhamento claro e transparente, da execução orçamentária e das finanças públicas, devendo-se ressaltar que dar publicidade não é necessariamente ser transparente, é preciso que as informações sejam compreendidas (CRUZ et al., 2009).

"A gestão fiscal refere-se à relação existente entre receitas e despesas públicas. No Brasil, durante um longo período essa relação apresentou-se desequilibrada para muitos órgãos e entes da Administração Pública brasileira" (CRUZ et al., 2009). Mais recentemente é que esse cenário tem sofrido mudanças e gradativamente busca-se uma maior transparência da gestão fiscal pública.

Discussões em torno da transparência fiscal no Brasil reportam-se à LRF (CRUZ, 2012); no entanto, a Constituição Federal de 1988, no art. 5ำ, incisos XXXIII, XXXIV e LXXII, já tratava da exigência da transparência de informações por órgãos da administração pública, como exemplo, cita-se o Inciso XXXIII o qual assegura que 'todos têm direito a receber dos órgãos públicos informações de seu interesse particular, ou de interesse coletivo ou geral, que serão prestadas no prazo da lei, sob pena de responsabilidade, ressalvadas aquelas 
cujo sigilo seja imprescindível à segurança da sociedade e do Estado'. Mas, foi a LRF que regulamentou de forma mais detalhada a divulgação de informações relativas à gestão fiscal, que obriga todas as esferas governamentais.

Nesse sentido, a LRF surge como uma exigência para entes públicos, em todas as esferas de poder, divulgarem em 'meio eletrônico de acesso público' todos os seus atos de gestão, conforme preconiza o artigo 48, capítulo IX, seção I, considerando instrumento de transparência da gestão fiscal: os planos, orçamentos e leis de diretrizes orçamentárias; as prestações de contas e o respectivo parecer prévio; o Relatório Resumido da Execução Orçamentária e o Relatório de Gestão Fiscal; e as versões simplificadas desses documentos.

A Lei Complementar no 131, de 2009, conhecida como Lei da Transparência, alterou a LRF e trouxe instrumentos de incentivo à participação popular e realização de audiências públicas durante os processos de elaboração e discussão dos planos, lei de diretrizes orçamentárias e orçamentos, e outras modificações relacionadas à transparência e o acesso a informações observadas nos artigos 48, 48-A, 73-A, 73-B e 73-C da LRF.

Ainda seguindo as novas diretrizes da LRF/2000, deverá haver a liberação ao pleno conhecimento e acompanhamento da sociedade, em tempo real, de informações pormenorizadas sobre a execução orçamentária e financeira, em meios eletrônicos de acesso público. Em relação à despesa, será observada a disponibilização de informações sobre todos os atos praticados pelas unidades gestoras no decorrer da execução da despesa, no momento de sua realização, com a disponibilização mínima dos dados referentes ao número do correspondente processo, ao bem fornecido ou ao serviço prestado, a pessoa física ou jurídica beneficiária do pagamento e, quando for o caso, ao procedimento licitatório realizado; e em relação a receita, o lançamento e o recebimento de toda a receita das unidades gestoras, inclusive referente a recursos extraordinários.

Outra novidade trazida pela Lei da Transparência, regulamentada pelo Decreto $n^{\circ} 7.185 / 2010$, é a adoção de sistema integrado de administração financeira e controle, que atenda a padrão mínimo de qualidade estabelecido pelo Poder Executivo da União e ao disposto no art. 48-A da LRF. Conforme Ribeiro et al. (2012), estudos realizados no Brasil e no exterior por diversos autores, (SANTANA JÚNIOR, 2008) chegaram à conclusão que há déficit de accountability na gestão pública, em todas as esferas do governo.

Apesar disso, a transparência fiscal tem sido considerada ultimamente como uma possibilidade para solucionar problemas como desequilíbrio fiscal, aumento da dívida pública e corrupção. Mesmo a LRF não tendo como principal objetivo a melhoria da gestão pública, mas o equilíbrio das contas públicas, a gestão por resultados vem sendo cada vez mais cobrada e inserida na esfera pública. A LRF surgiu com o intuito de inibir o excesso do endividamento público, trazendo como princípio não se gastar mais do que se arrecada.

\section{A Lei de Acesso à Informação (LAI)}

A Reforma Administrativa do Estado, em 1995, propiciou uma modernização em sua estrutura administrativa, inclusive tendo ocorrido a implantação de ferramentas de comunicação, a exemplo do 
governo eletrônico. Em 2009, foi aprovada a Lei da Transparência, a qual acrescentou dispositivos à $\mathrm{LRF} / 2000$.

Dentre outros dispositivos, a lei procurou assegurar a transparência também mediante o incentivo à participação popular e realização de audiências públicas, durante os processos de elaboração e discussão dos planos, lei de diretrizes orçamentárias e orçamentos, além da liberação para pleno conhecimento e acompanhamento da sociedade, em tempo real, de informações pormenorizadas sobre a execução orçamentária e financeira, em meios eletrônicos de acesso público e a adoção de sistema integrado de administração financeira e controle, que atenda ao padrão mínimo de qualidade estabelecido pelo Poder Executivo da União e ao disposto no art. 48-A da referida lei, hoje obrigatória a todos os entes da federação.

A Lei da Transparência, que começou a vigorar desde maio de 2010, abrangendo quase toda a esfera pública, ou seja, União, Estados e municípios com mais de 100 mil habitantes, a partir de maio de 2011 foi estendida aos municípios com população entre 50 mil e 100 mil habitantes e finalmente até maio de 2013 foram integrados os municípios com até 50 mil habitantes, tornando-se a partir de então obrigatória para todos os entes da federação.

O acesso de todos os cidadãos brasileiros às informações públicas sob a guarda do Estado é um direito fundamental e está previsto na Constituição Federal de 1988. Entretanto, foi com a Lei de Acesso à Informação (LAI/2011), que esse direito de acesso à informação foi regulamentado, visto que criou mecanismos para possibilitar que qualquer pessoa, sem motivação, receba informações públicas requeridas a órgãos e entidades.

Um dos princípios da lei é que a publicidade e a transparência das informações é a regra, e o sigilo; a exceção. $\mathrm{O}$ acesso à informação é restringido apenas em situações específicas, como nos casos em que a divulgação das informações coloque em risco a segurança da população, do estado, ou a defesa do território nacional.

Ela é de cumprimento obrigatório para todos os entes, de todas as esferas governamentais, produzindo grandes impactos na gestão pública, exigindo para sua efetiva implementação a adoção de uma série de medidas que podem, por meio do programa Brasil Transparente, ser auxiliadas pela CGU, que é o órgão responsável pelo monitoramento da sua aplicação e do Decreto no 7.724/2012, que a regulamenta no Poder Executivo Federal. A CGU ainda atua como instância recursal no Poder Executivo Federal, nos termos do artigo 16 da Lei no 12.527 e do art. 23 do Decreto no 7.724 .

A obrigatoriedade de o poder público prestar informações está relacionada tanto com a denominada Transparência Ativa (tornar públicas, espontaneamente, informações coletivo ou geral) como com a Transparência Passiva (o dever de informar mediante solicitação). Transparência ativa é o dever de entidades e órgãos públicos divulgarem proativamente e espontaneamente informações de interesse coletivo produzidas ou mantidas por eles em local físico de fácil acesso e via internet. 0 artigo 8으 da LAl, nos incisos de I a VI, estabelece e discrimina as informações mínimas do papel ativo do Estado quando afirma que a Administração Pública deve promover, 'independentemente de requerimentos, a divulgação em local de fácil 
acesso, no âmbito de suas competências, de informações de interesse coletivo ou geral por eles produzidas ou custodiadas'.

No mínimo, as informações divulgadas devem conter: registro das competências e estrutura organizacional, endereços e telefones das respectivas unidades e horários de atendimento ao público; registros de quaisquer repasses ou transferências de recursos financeiros; registros das despesas; informações concernentes a procedimentos licitatórios, inclusive os respectivos editais e resultados, bem como a todos os contratos celebrados; dados gerais para o acompanhamento de programas, ações, projetos e obras de órgãos e entidades; e respostas às perguntas mais frequentes da sociedade.

Entende-se como Transparência passiva o dever de os Órgãos públicos divulgarem informações sob sua posse, quando elas são formalmente solicitadas por internet, protocolados presencialmente ou por telefone. Divulgar espontaneamente o maior número possível de informações é mais vantajoso aos Órgãos e entidades públicas, visto que possibilita a redução da demanda e desta forma, consequentemente, o trabalho e os custos de processamento e gerenciamento dos pedidos de acesso.

$\mathrm{O}$ atendimento aos itens elencados contribuirá para avaliar a responsabilidade na divulgação de informações de forma espontânea ao público em geral em seus Portais da Transparência. Com relação aos Portais de Transparência, todas as informações disponíveis serão analisadas de acordo com a disponibilização em seus sítios eletrônicos. De acordo com a Lei de Acesso à Informação, os itens que deverão ser observados são:

Divulgação da estrutura organizacional, competências, legislação aplicável, principais cargos e seus ocupantes, endereço e telefones das unidades e horários de atendimento ao público, regulamentada pela LAI/2011 e Decreto no 7.724/2012;

Divulgação de programas, projetos, ações, obras e atividades, com indicação da unidade responsável, principais metas e resultados e, quando existentes, indicadores de resultado e impacto, regulamentada pela LAI/2011 e Decreto no 7.724/2012;

Divulgação de repasses ou transferências de recursos financeiros, regulamentada pela LAI/2011 e Decreto no 7.724/2012;

Divulgação da execução orçamentária e financeira das despesas detalhada, regulamentada pela LAI/2011 e Decreto no 7.724/2012;

Divulgação das licitações realizadas e em andamento, com editais, anexos e resultados, além dos contratos firmados e notas de empenho emitidas, regulamentada pela LAI/2011 e Decreto $n=7.724 / 2012$ - inclui notas de empenho emitidas;

Divulgação de respostas a perguntas mais frequentes da sociedade, regulamentada pela LAI/2011 e Decreto № 7.724/2012;

Divulgação da execução orçamentária e financeira das receitas detalhada, regulamentada pela Decreto no 7.724/2012;

Divulgação da remuneração e subsídio recebidos por ocupante de cargo, posto, graduação, função e emprego público, incluindo auxílios, ajudas de custo, jetons e quaisquer outras vantagens pecuniárias, bem como proventos de aposentadoria e pensões daqueles que estiverem na ativa, de maneira individualizada, conforme ato do Ministério do Planejamento, Orçamento e Gestão, regulamentada pela Decreto no 7.724/2012;

O Estado possui em seus sítios na Internet seção específica para a divulgação das informações, sendo essa uma regulamentação dada pelo Decreto no 7.724/2012;

O site do governo estadual possui banner na página inicial, dando acesso à seção específica para o Portal de Transparência, sendo essa uma regulamentação dada pelo Decreto no $7.724 / 2012$ 
Divulgação de contato da autoridade de monitoramento, designada nos termos do art. 40 da Lei no 12.527 , de 2011, e telefone e correio eletrônico do Serviço de Informações ao Cidadão - SIC, sendo essa uma regulamentação dada pelo Decreto no 7.724/2012;

Divulgação de programas financiados pelo Fundo de Amparo ao Trabalhador - FAT, sendo essa uma regulamentação dada pelo Decreto $n$ ㅇ $7.724 / 2012$, incluída pelo Decreto $\mathrm{n}$ 은 $8.408 / 2015$

\section{Indicadores econômicos}

A LRF estabelece normas de finanças públicas relacionadas a responsabilidade na gestão fiscal e determina que os entes públicos (federal, estadual e municipal) elaborem e publiquem o Anexo de Riscos Fiscais (ARF) e o Anexo de Metas Fiscais (AMF), que acompanham a Lei de Diretrizes Orçamentárias - LDO, e, periodicamente, o Relatório Resumido de Execução Orçamentária (RREO) e o Relatório Resumido de Gestão Fiscal (RGF), com o propósito de assegurar a transparência dos gastos públicos e a consecução das metas fiscais, com a permanente observância dos limites fixados pela lei.

Os indicadores são ferramentas úteis para a gestão pública, tanto para revelar a situação atual das políticas, como para produzir subsídios que permitam acompanhar sua evolução. Nesse sentido, a LRF auxilia todos os gestores na gestão dos recursos públicos, com regras claras e precisas relacionadas à gestão da receita e da despesa públicas, ao endividamento e à gestão do patrimônio público, como também, consagra a transparência da gestão como mecanismo de controle social, com a obrigatoriedade da publicação de relatórios e demonstrativos da execução orçamentária, demonstrando à sociedade a utilização dos recursos públicos.

Merecem destaque alguns princípios e normas estabelecidos pela LRF, como o limite de gasto com pessoal: a lei fixa limites para essa despesa em relação à receita corrente líquida para os três Poderes e para cada nível de governo; limites para o endividamento público: serão estabelecidos pelo Senado Federal por proposta do Presidente da República; definição de metas fiscais anuais e para os três exercícios seguintes; mecanismos de compensação para despesas de caráter permanente: o governante não poderá criar uma despesa continuada (por prazo superior a dois anos) sem indicar uma fonte de receita ou uma redução de outra despesa; e mecanismo para controle das finanças públicas em anos de eleição, visto que a Lei impede a contratação de operações de crédito por antecipação de receita orçamentária (ARO) no último ano de mandato e proíbe o aumento das despesas com pessoal nos 180 dias que antecedem o final do mandato.

A Receita Corrente Líquida ( $R C L$ ) é a base de cálculo de todos os limites estabelecidos pela LRF, evidenciados em seu RGF. Portanto, sobre a RCL são calculados os limites impostos para as despesas com pessoal, de gastos previdenciários e de endividamento.

A LRF traz ao longo de seu texto, seja direta ou indiretamente, alguns indicadores econômicos relacionados ao controle dos gastos públicos, tais como: Receita Total, Despesa Total, Resultado Nominal, Resultado Primário, Receita Corrente Líquida, Ativo Real, Passivo Real e Dívida Consolidada (SANTANA JÚNIOR, 2008). Verifica-se, também, a preocupação com mais um indicador, o da evolução do patrimônio líquido dos entes públicos. 


\section{Receita Corrente Líquida (RCL)}

Segundo o art. 2ํ, IV, da LRF/2000, a RCL é o somatório das receitas tributárias, de contribuições, patrimoniais, agropecuárias, industriais, de serviços, transferências correntes e outras receitas correntes do ente da Federação, deduzidos alguns itens exaustivamente explicitados pela própria LRF, não cabendo interpretações que extrapolem os dispositivos legais. Deverá ser apurada somando-se as receitas arrecadadas no mês de referência e nos onze anteriores.

A RCL é divulgada bimestralmente, no Demonstrativo da Receita Corrente Líquida, disciplinado pelo Manual de Demonstrativos Fiscais (MDF), da Secretaria do Tesouro Nacional e integra o Relatório Resumido de Execução Orçamentária (RREO), publicado até trinta dias após o encerramento de cada bimestre. De acordo com o MDF, seu principal objetivo é servir de parâmetro para os limites estabelecidos pelo LRF da despesa total com pessoal, da dívida consolidada líquida, entre outros.

\section{Despesa Total de Pessoal (DTP)}

De acordo com a LRF, a despesa total com pessoal é o somatório dos gastos do ente da Federação com os ativos, os inativos e os pensionistas, relativos a mandatos eletivos, cargos, funções ou empregos, civis, militares e de membros de Poder, com quaisquer espécies remuneratórias, tais como vencimentos e vantagens, fixas e variáveis, subsídios, proventos da aposentadoria, reformas e pensões, inclusive adicionais, gratificações, horas extras e vantagens pessoais de qualquer natureza, bem como encargos sociais e contribuições recolhidas pelo ente às entidades de previdência.

A DTP é divulgada quadrimestralmente, como determinado pela LRF, até trinta dias após o encerramento do período a que corresponder. Está contemplada no Demonstrativo da Despesa com Pessoal, disciplinado pelo MDF, e é parte integrante do Relatório de Gestão Fiscal (RGF). Este demonstrativo deverá conter valores da despesa com pessoal do Poder/Órgão executada nos últimos 12 (doze) meses e o percentual da despesa total com pessoal em relação à $\mathrm{RCL}$, e os limites máximo, prudencial e de alerta estabelecidos conforme a Lei de Responsabilidade Fiscal.

Segundo o MDF, 'o demonstrativo visa à transparência da despesa com pessoal de cada um dos Poderes e órgãos com autonomia administrativa, orçamentária e financeira conferida na forma da Constituição, notadamente quanto à adequação aos limites de que trata a Lei de Responsabilidade Fiscal LRF'.

\section{Dívida Consolidada Líquida (DCL)}

De acordo com o MDF, a DCL representa o montante da Dívida Consolidada (DC) deduzido o saldo relativo aos haveres financeiros (disponibilidade de caixa e demais haveres financeiros). Por sua vez, a Dívida Consolidada (DC) ou fundada, para fins fiscais, corresponde ao montante total das obrigações financeiras. Segunda a LRF, 'dívida pública consolidada ou fundada é o montante total, apurado sem duplicidade, das obrigações financeiras do ente da Federação, assumidas em virtude de leis, contratos, convênios ou tratados e da realização de operações de crédito, para amortização em prazo superior a doze meses. 
O Demonstrativo da Dívida Consolidada Líquida compõe o Relatório de Gestão Fiscal, divulgado quadrimestralmente, e contém informações sobre a Dívida Consolidada (detalhada em Dívida Mobiliária, Dívida Contratual, Precatórios Posteriores a 05/05/2000 e Outras Dívidas); as Deduções (detalhadas em Disponibilidade de Caixa e Demais Haveres Financeiros); a Dívida Consolidada Líquida e o percentual apurado com base na Receita Corrente Líquida.

Segundo o MDF, a DCL visa assegurar a transparência das obrigações contraídas pelos entes da Federação e verificar os limites de endividamento de que trata a legislação e outras informações relevantes, que não poderão exceder a 2 vezes a RCL, no caso dos Estados e do Distrito Federal, e 1,2 vezes a RCL, no caso dos Municípios, em conformidade com a Resolução do Senado Federal no 40, de 20/12/2001.

\section{Limites da Relação DCL/RCL e DTP/RCL}

A Resolução do Senado Federal no 40, de 20/12/2001, impõe que a relação DCL/RCL seja menor que 2,0 no caso dos estados e distrito federal e menor do que 1,2 no caso dos municípios. A despesa total com pessoal, em cada período de apuração e em cada ente da Federação, não poderá exceder os percentuais determinados da receita corrente líquida, que são, na espera Federal: 2,5\% para o Legislativo; 6\% para o Judiciário e 40,9\% para o Executivo e 0,6\% para o Ministério Público da União; Nos Estados, 3\% para o Legislativo, 6\% para o Judiciário, 49\% para o Executivo e 2\% para o Ministério Público dos Estados; Para os Municípios, 6\% para o Legislativo e 54\% para o Executivo, de acordo com o art. 20 da LRF (2000), observando as despesas não computadas. Estes são os limites máximo da despesa. O limite prudencial corresponde à 95\% deste teto e o limite de alerta, a $90 \%$.

\section{METODOLOGIA}

No que se refere aos objetivos propostos, a presente pesquisa assume caráter descritivo que, conforme Gil (2008) "têm como objetivo primordial a descrição das características de determinada população ou fenômeno ou o estabelecimento de relações entre as variáveis". Quanto aos procedimentos, a pesquisa foi fundamentada em material bibliográfico e documental concernente aos objetivos supracitados, através de consultas realizadas em livros, periódicos, artigos, dissertações, teses, legislação e sites da internet.

Com relação à abordagem do problema, o método adotado foi o qualitativo-quantitativo, uma vez que a pesquisa qualitativa é fundamentalmente interpretativa acerca da realidade em estudo, o que significa dizer que o pesquisador interpreta os dados a partir da descrição de um fato ou cenário. Na pesquisa quantitativa, o problema é mais bem trabalhado ao entender quais fatores ou variáveis influenciam um resultado (CRESWELL, 2010). Coletou-se os Índices de Transparência do MPF e da CGU dos 26 estados brasileiros e do Distrito Federal (DF). Primeiramente foram coletados os dados dos Índices de Transparência do MPF e da CGU.

O Índice Nacional de Transparência MPF (INT), divulgado pelo Ministério Público Federal é mensurado a partir da aplicação de um questionário elaborado por representantes do Ministério Público 
Federal (MPF), Conselho Nacional do Ministério Público (CNMP), Controladoria Geral da União (CGU), Tribunal de Contas da União (TCU), Secretaria do Tesouro Nacional (STN), Associação dos Membros dos Tribunais de Contas (ATRICON), Banco Central, entre outras instituições de controle e fiscalização, abordando os seguintes pontos: Geral, Receitas, Despesas, Licitações e Contratos, Relatórios, Transparência Passiva, Serviços de Atendimento ao Cidadão (e-Sic), Divulgação da Estrutura e Forma de Contato e Boas Práticas de Transparência. As questões respondidas possuem peso diferenciado de acordo com a sua importância, o que definiu a nota a ser atribuída, que varia entre 0 a 10.

A Escala Brasil Transparente (EBT) é divulgada pelo Controladoria Geral da União, e é um indicador que tem o objetivo de avaliar o grau de cumprimento de dispositivos da Lei de Acesso à Informação (LAI) ${ }^{1}$. Posteriormente, após a identificação do ranking dos Estados em relação aos índices de transparência supracitados, buscou-se analisar, por meio do Teste de Coeficiente de Correlação Por Ordem Spearman e análise de regressão, se há correlação entre os mesmos e indicadores econômicos, mais notadamente, Despesa Total de Pessoal (DTP)/Receita Corrente Líquida (RCL) e Dívida Consolidada Líquida (DCL) /Receita Corrente Líquida (RCL), referentes ao último quadrimestre de 2015. Os indicadores econômicos foram identificados no site do STN.

\section{RESULTADOS}

Um dos objetivos do presente estudo é verificar se existe correlação, entre indicadores econômicos e os índices nacionais de transparência do MPF e da CGU evidenciados para os 26 estados brasileiros mais o Distrito Federal. Para atingir este intuito foi feita uma análise entre o Índice Nacional de Transparência (INTMPF) e dois indicadores: índice de Despesa Total com Pessoal (DTP) em relação a Receita Corrente Liquida $(R C L)$ e índice de Despesa Corrente Líquida (DCL) em relação a Receita Corrente Líquida ( $R C L)$.

Da mesma forma procedeu-se a uma verificação entre o índice Escala Brasil Transparente (EBT-CGU) e índice de Despesa Total com Pessoal (DTP) em relação a Receita Corrente Liquida (RCL) e índice de Despesa Corrente Líquida (DCL) em relação a Receita Corrente Líquida (RCL). Os dados coletados e as informações observadas estão evidenciadas a seguir.

\section{Dados}

Na tabela 1 é demonstrada a pontuação apresentada pelo índice Nacional de Transparência e pela Escala Brasileira de Transparência, para cada estado brasileiro, seguida da estatística descritiva dos dados. A tabela 2 mostra medidas da estatística descritiva dos índices. Observa-se que o estado de Roraima apresenta o menor índice INT, enquanto Sergipe apresenta o menor índice EBT. O estado do Espírito Santo é o único que apresenta nota máxima em ambos os índices. A tabela 2 foi nomeada 'Estatística descritiva do INT e do $\mathrm{EBT}^{\prime}$.

1É apurado por meio de um questionário, que avalia os seguintes pontos: Regulamentação da Lei de Acesso e Transparência Passiva, abordando 12 pontos, com preenchimento binário ( $\mathrm{sim} /$ não), salvo quando não existir um site ou este estiver fora do ar, podendo nesse caso existir os termos 'Não Localizado' ou 'Site Fora do AR', e a nota final varia de 0 a 10. 
Tabela 1: Índices INT e EBT apresentados por cada estado.

\begin{tabular}{|c|c|c|}
\hline ESTADO & INT & EBT \\
\hline Rio de Janeiro & 8,70 & 7,08 \\
\hline Piauí & 8,30 & 8,47 \\
\hline Maranhão & 8,50 & 10,00 \\
\hline Paraná & 8,70 & 9,31 \\
\hline Espírito Santo & 10,00 & 10,00 \\
\hline Amapá & 8,00 & 0,00 \\
\hline Rondônia & 10,00 & 4,44 \\
\hline Ceará & 10,00 & 8,06 \\
\hline Pernambuco & 8,80 & 6,67 \\
\hline São Paulo & 9,70 & 10,00 \\
\hline Distrito Federal & 7,60 & 10,00 \\
\hline Roraima & 3,80 & 2,50 \\
\hline Pará & 8,30 & 9,03 \\
\hline Bahia & 4,10 & 10,00 \\
\hline Sergipe & 8,10 & 2,08 \\
\hline Minas Gerais & 9,20 & 10,00 \\
\hline Amazonas & 7,50 & 1,39 \\
\hline Santa Catarina & 9,70 & 6,94 \\
\hline Goiás & 9,80 & 10,00 \\
\hline Alagoas & 7,60 & 7,92 \\
\hline Acre & 5,60 & 3,33 \\
\hline Rio Grande do Sul & 8,60 & 8,89 \\
\hline Mato grosso & 8,10 & 8,61 \\
\hline Paraíba & 7,50 & 8,75 \\
\hline Tocantins & 9,80 & 10,00 \\
\hline Rio Grande do Norte & 9,20 & 8,19 \\
\hline Mato Grosso do Sul & 9,10 & 2,50 \\
\hline
\end{tabular}

Tabela 2: Estatística descritiva do INT e do EBT.

\begin{tabular}{|l|r|r|}
\hline & INT & EBT \\
\hline Média & 8,307 & 7,191 \\
\hline Erro padrão & 0,310 & 0,609 \\
\hline Mediana & 8,6 & 8,47 \\
\hline Modo & 10 & 1,613 \\
\hline Desvio padrão & 2,602 & 10 \\
\hline Variância da amostra & 2,525 & 3,166 \\
\hline Curtose & $-1,573$ & 10,022 \\
\hline Assimetria & 6,2 & $-0,345$ \\
\hline Intervalo & 3,8 & $-1,017$ \\
\hline Mínimo & 10 & 10 \\
\hline Máximo & 224,3 & 0 \\
\hline Soma & 27 & 10 \\
\hline Contagem & 27 \\
\hline
\end{tabular}

Os elementos de gestão fiscal utilizados neste trabalho foram obtidos no site do Sistema de Informações Contábeis e Fiscais do Setor Público Brasileiro (SICONFI), que contém os dados declarados pelos representantes legais das prefeituras e estados, referentes ao último quadrimestre de 2015. A tabela 3 demonstra os indicadores de gestão utilizados nos testes, e a tabela 4, a estatística descritiva dos indicadores econômicos, com receitas e despesas mensuradas em reais. O estado do Rio Grande do Sul apresenta a maior relação $\mathrm{DCL} / \mathrm{RCL}$, embora outros estados estejam muito perto do limite recomendado. O Rio Grande do Norte tem o menor percentual, todavia, sua relação DTP/RCL sugere um comprometimento, proporcionalmente maior do que o Rio Grande do Sul.

Tabela 3: Indicadores de gestão.

\begin{tabular}{|c|c|c|c|c|c|}
\hline ESTADO & RCL & DTP & DCL & DTP/RCL & DCL/RCL \\
\hline & (a) & (b) & (c) & (d)/(c) & (e)/(c) \\
\hline
\end{tabular}




\begin{tabular}{|c|c|c|c|c|c|}
\hline Rio de Janeiro & 51.224 .316 .994 & 17.150 .989 .582 & 101.307 .562 .389 & 0,33 & 1,98 \\
\hline Piauí & 6.600 .087 .436 & 2.818 .051 .035 & 3.762 .714 .199 & 0,43 & 0,57 \\
\hline Maranhão & 10.712 .347 .552 & 4.592 .592 .579 & 6.443 .795 .621 & 0,43 & 0,60 \\
\hline Paraná & 31.807 .637 .346 & 13.771 .244 .733 & 15.432 .131 .336 & 0,43 & 0,49 \\
\hline Espírito Santo & 11.951 .594 .613 & 5.185 .589 .496 & 3.748 .618 .993 & 0,43 & 0,31 \\
\hline Amapá & 3.875 .537 .367 & 1.682 .615 .181 & 1.063 .794 .175 & 0,43 & 0,27 \\
\hline Rondônia & 5.825 .194 .566 & 2.585 .909 .661 & 3.722 .889 .164 & 0,44 & 0,64 \\
\hline Ceará & 15.176 .440 .113 & 6.970 .859 .881 & 9.369 .812 .567 & 0,46 & 0,62 \\
\hline Pernambuco & 19.648 .437 .023 & 9.075 .557 .365 & 12.215 .360 .982 & 0,46 & 0,62 \\
\hline São Paulo & 140.398 .953 .319 & 64.974 .618 .722 & 235.645 .413 .306 & 0,46 & 1,68 \\
\hline Distrito Federal & 18.461 .481 .002 & 8.635 .835 .810 & 4.657 .949 .947 & 0,47 & 0,25 \\
\hline Roraima & 2.824 .662 .615 & 1.336 .251 .152 & 332.350 .189 & 0,47 & 0,12 \\
\hline Pará & 16.789 .901 .790 & 7.947 .028 .738 & 2.020 .940 .562 & 0,47 & 0,12 \\
\hline Bahia & 27.207 .610 .585 & 12.952 .774 .613 & 16.136 .539 .853 & 0,48 & 0,59 \\
\hline Sergipe & 6.353 .339 .375 & 3.037 .924 .180 & 4.385 .703 .604 & 0,48 & 0,69 \\
\hline Minas Gerais & 51.643 .235 .767 & 24.740 .131 .048 & 102.592 .255 .535 & 0,48 & 1,99 \\
\hline Amazonas & 10.998 .994 .389 & 5.277 .716 .373 & 5.259 .411 .122 & 0,48 & 0,48 \\
\hline Santa Catarina & 19.409 .870 .961 & 9.384 .427 .017 & 10.295 .408 .629 & 0,48 & 0,53 \\
\hline Goiás & 17.361 .933 .085 & 8.409 .440 .060 & 17.119 .934 .769 & 0,48 & 0,99 \\
\hline Alagoas & 6.311 .577 .937 & 3.059 .906 .480 & 10.710 .404 .398 & 0,48 & 1,70 \\
\hline Acre & 3.949 .107 .687 & 1.927 .024 .333 & 3.822 .957 .500 & 0,49 & 0,97 \\
\hline Rio Grande do Sul & 30.139 .172 .171 & 14.821 .455 .670 & 68.486 .044 .087 & 0,49 & 2,27 \\
\hline Mato grosso & 11.644 .432 .986 & 5.791 .517 .009 & 5.676 .297 .275 & 0,50 & 0,49 \\
\hline Paraíba & 7.973 .372 .465 & 4.106 .920 .912 & 3.297 .120 .097 & 0,52 & 0,41 \\
\hline Tocantins & 6.304 .771 .945 & 3.296 .248 .869 & 2.523 .586 .133 & 0,52 & 0,40 \\
\hline Rio Grande do Norte & 7.996 .956 .929 & 4.200 .948 .738 & 722.653 .820 & 0,53 & 0,09 \\
\hline Mato Grosso do Sul & 8.320 .781 .589 & 4.591 .452 .094 & 7.627 .462 .146 & 0,55 & 0,92 \\
\hline
\end{tabular}

Tabela 4: Estatística descritiva dos indicadores de gestão fiscal DTP/RCL e DCL/RCL.

\begin{tabular}{|l|r|r|}
\hline & $D T P / R C L$ & $D C L / R C L$ \\
\hline Média & 0,470 & 0,770 \\
\hline Erro padrão & 0,008 & 0,118 \\
\hline Mediana & 0,476 & 0,593 \\
\hline Modo & 0,000 & 0,000 \\
\hline Desvio padrão & 0,041 & 0,613 \\
\hline Variância da amostra & 0,002 & 0,375 \\
\hline Curtose & 3,701 & 0,634 \\
\hline Assimetria & $-1,076$ & 1,284 \\
\hline Intervalo & 0,217 & 2,182 \\
\hline Mínimo & 0,335 & 0,090 \\
\hline Máximo & 0,552 & 2,272 \\
\hline Soma & 12,691 & 20,780 \\
\hline Contagem & 27 & 27 \\
\hline
\end{tabular}

\section{Regressão}

Para verificar a relação de dependência entre os indicadores de transparência (INT e EBT) frente aos indicadores de gestão fiscal (DTP/RCL e $D C L / R C L)$, utilizou-se a seguinte equação de regressão, que é dada por $Y_{i}=\beta_{0}+\beta_{1} X_{1 i}+\beta_{2} X_{2 i}+u_{i}$, onde, $Y$ é logaritmo ${ }^{2}$ do Índice de Transparência (INT ou EBT), $X_{1 i}$ é a relação $D T P / R C L$ e $X_{2 i}$ é a relação $D C L / R C L$ e $u_{i}$ é o termo de erro. Como os indicadores de transparência apresentam resultados que variam de 0 a 10 e os indicadores de gestão fiscal variam entre 0 a 2,2, optou-se por usar o logaritmo do INT e EBT, para melhor apropriação da Regressão. A tabela 5 apresenta as variáveis que serão utilizados nos modelos.

${ }^{2} \mathrm{O}$ uso do logaritmo teve por objetivo suavizar os dados visto que os indicadores de transparência apresentam resultados que variam de 0 a 10 e os indicadores de gestão fiscal variam entre 0 a 2,2, deixando-os compatíveis com a medida das variáveis explicativas. 
Tabela 5: INT e EBT em logaritmo.

\begin{tabular}{|c|c|c|c|c|c|c|}
\hline ESTADO & INT & INT $_{\text {LOG }}$ & EBT & EBT LOG $_{\text {L }}$ & DTP/RCL & $\mathrm{DCL} / \mathrm{RCL}$ \\
\hline & (a) & LOG (a) & (b) & LOG(b) & & \\
\hline Rio de Janeiro & 8,70 & 0,94 & 7,08 & 0,85 & 0,33 & 1,98 \\
\hline Piauí & 8,30 & 0,92 & 8,47 & 0,93 & 0,43 & 0,57 \\
\hline Maranhão & 8,50 & 0,93 & 10,00 & 1,00 & 0,43 & 0,60 \\
\hline Paraná & 8,70 & 0,94 & 9,31 & 0,97 & 0,43 & 0,49 \\
\hline Espírito Santo & 10,00 & 1,00 & 10,00 & 1,00 & 0,43 & 0,31 \\
\hline Amapá & 8,00 & 0,90 & 0,00 & 0,00 & 0,43 & 0,27 \\
\hline Rondônia & 10,00 & 1,00 & 4,44 & 0,65 & 0,44 & 0,64 \\
\hline Ceará & 10,00 & 1,00 & 8,06 & 0,91 & 0,46 & 0,62 \\
\hline Pernambuco & 8,80 & 0,94 & 6,67 & 0,82 & 0,46 & 0,62 \\
\hline São Paulo & 9,70 & 0,99 & 10,00 & 1,00 & 0,46 & 1,68 \\
\hline Distrito Federal & 7,60 & 0,88 & 10,00 & 1,00 & 0,47 & 0,25 \\
\hline Roraima & 3,80 & 0,58 & 2,50 & 0,40 & 0,47 & 0,12 \\
\hline Pará & 8,30 & 0,92 & 9,03 & 0,96 & 0,47 & 0,12 \\
\hline Bahia & 4,10 & 0,61 & 10,00 & 1,00 & 0,48 & 0,59 \\
\hline Sergipe & 8,10 & 0,91 & 2,08 & 0,32 & 0,48 & 0,69 \\
\hline Minas Gerais & 9,20 & 0,96 & 10,00 & 1,00 & 0,48 & 1,99 \\
\hline Amazonas & 7,50 & 0,88 & 1,39 & 0,14 & 0,48 & 0,48 \\
\hline Santa Catarina & 9,70 & 0,99 & 6,94 & 0,84 & 0,48 & 0,53 \\
\hline Goiás & 9,80 & 0,99 & 10,00 & 1,00 & 0,48 & 0,99 \\
\hline Alagoas & 7,60 & 0,88 & 7,92 & 0,90 & 0,48 & 1,70 \\
\hline Acre & 5,60 & 0,75 & 3,33 & 0,52 & 0,49 & 0,97 \\
\hline Rio Grande do Sul & 8,60 & 0,93 & 8,89 & 0,95 & 0,49 & 2,27 \\
\hline Mato grosso & 8,10 & 0,91 & 8,61 & 0,94 & 0,50 & 0,49 \\
\hline Paraíba & 7,50 & 0,88 & 8,75 & 0,94 & 0,52 & 0,41 \\
\hline Tocantins & 9,80 & 0,99 & 10,00 & 1,00 & 0,52 & 0,40 \\
\hline Rio Grande do Norte & 9,20 & 0,96 & 8,19 & 0,91 & 0,53 & 0,09 \\
\hline Mato Grosso do Sul & 9,10 & 0,96 & 2,50 & 0,40 & 0,55 & 0,92 \\
\hline
\end{tabular}

\section{Regressão Índice Nacional de Transparência (INT) e os indicadores de gestão fiscal}

Considerando a regressão da Equação proposta anteriormente, com a variável dependente $\left(Y_{i}\right)$ como o Índice Nacional de Transparência (INT) e os indicadores de gestão fiscal como variáveis independentes, obteve-se os resultados apresentados na tabela 6, que foi denominada 'Regressão INT-DTP/RCL e DCL/RCL, apresentando estatística de regressão. Os parâmetros obtidos não são significativos ao nível de significância de $5 \%$, a exceção do intercepto. Logo, este modelo sugere que a melhor projeção de $Y$ é a média das variáveis explicativas. $O$ baixo poder de explicação do coeficiente de determinação aponta para ausência de correlação significativa entre as variáveis.

Tabela 6: Regressão INT-DTP/RCL e DCL/RCL.

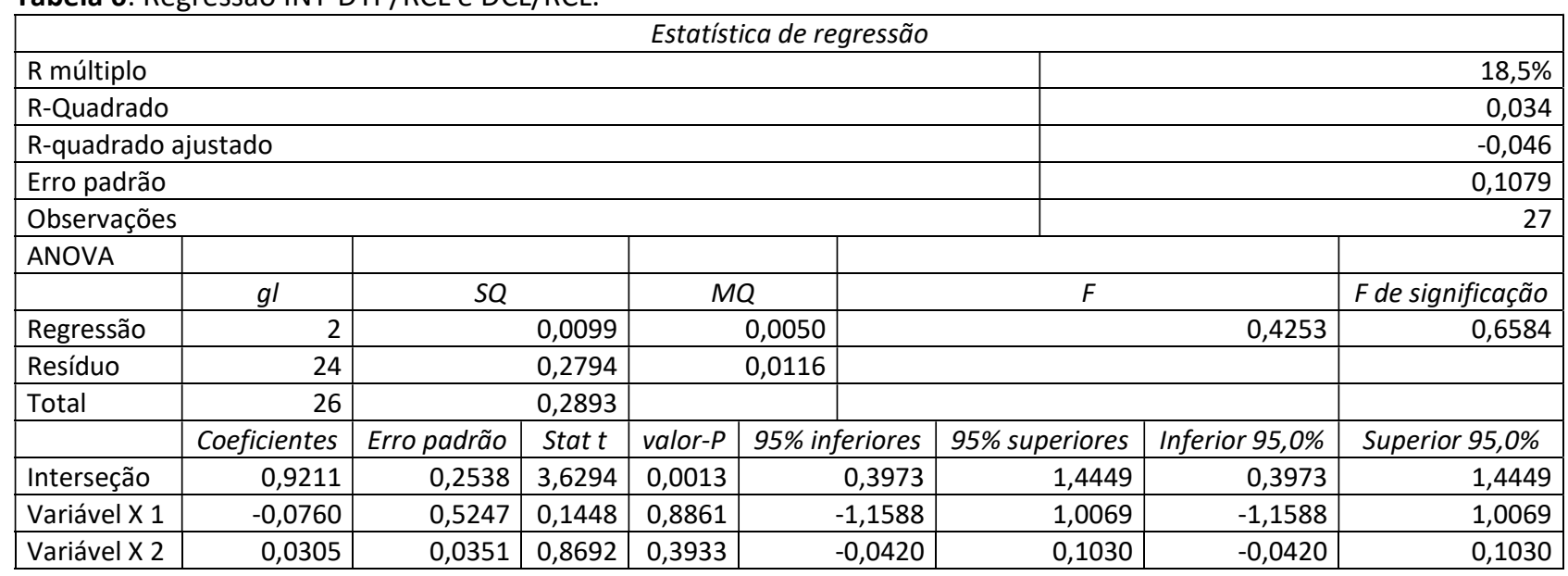




\section{Regressão Escala Brasil Transparente e os indicadores de gestão fiscal}

Fazendo uso, novamente, do modelo dado pela equação proposta, agora considerando $Y_{i}$ como sendo o logaritmo do índice EBT a tabela 7 mostra os resultados da regressão. Os parâmetros obtidos não são significativos ao nível de significância de 5\%. Logo, evidencia-se que deve ser avaliado o emprego de outras variáveis independentes, que permitam a construção de um modelo mais adequado para explicação da Escala Brasil Transparência (EBT). O teste F, com nível de significação de 61,06\%, mostra que os parâmetros não são significativos. Observa-se que a relação DTP/RCL atua no sentido contrário da variável dependente, isto é, o aumento dessa variável impõe uma redução na variável dependente da ordem de 7\% e $9 \%$ para cada modelo.

Tabela 7: Regressão EBT-DTP/RCL e DCL/RCL.

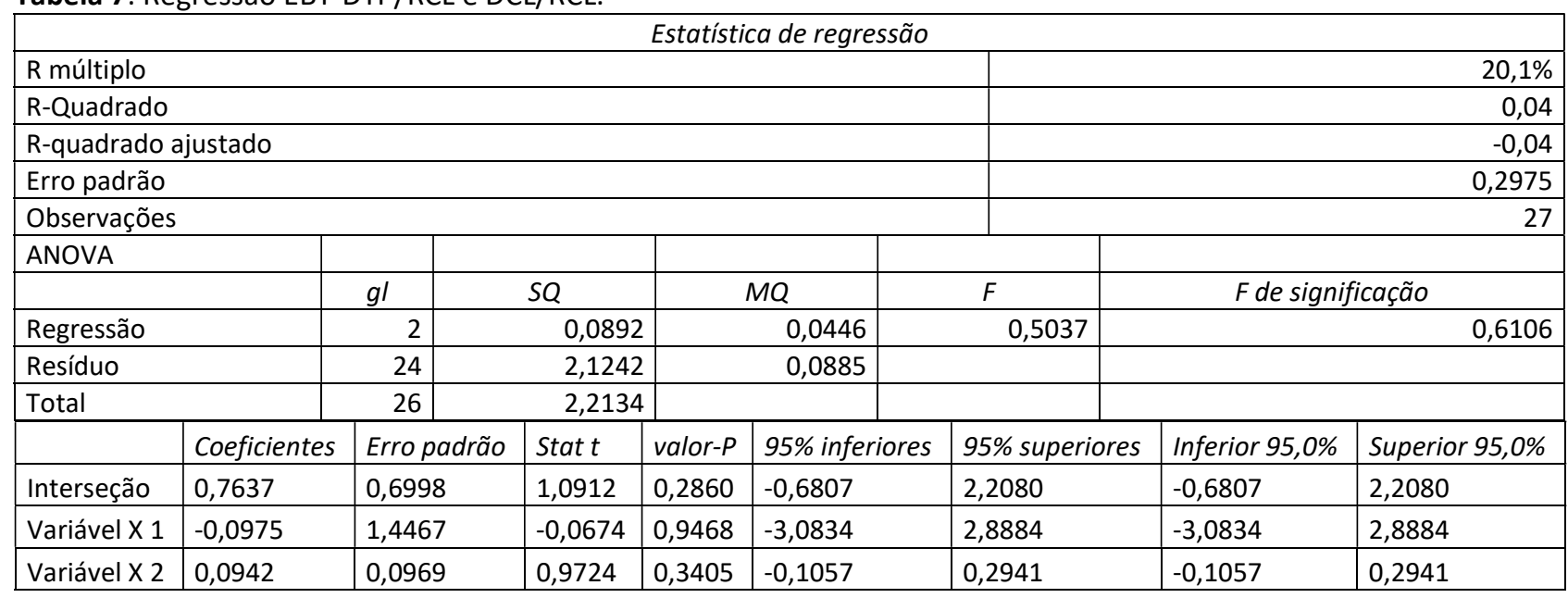

\section{Teste de Coeficientes de Correlação por Ordem Spearman}

No sentido de ratificar ou refutar os resultados obtidos para os indicadores de transparência (INT e $E B T$ ), explicados pelos indicadores de gestão fiscal (DTP/RCL e $D C L / R C L)$, procedeu-se ao teste não paramétrico de Coeficientes de Correlação por Ordem Spearman. Este teste considera o posto ocupado por cada um dos Estados da Federação no ranking de resultados do índice de Transparência do Ministério Público Federal (INT) e do Índice de Transparência da Controladoria Geral da União (CGU) e dos indicadores de gestão fiscal, considerando o posto 1 o de melhor resultado.

O coeficiente de correlação de postos é dado por $\rho=1-\frac{6 \Sigma d_{i}^{2}}{n\left(n^{2}-1\right)}$, onde, $n$ é o número de pares $\left(x_{i}, y_{i}\right)$ e $d_{i}$ é a diferença entre o posto de $x_{i}$ dentre os valores de $x$ e o posto $y_{i}$ dentre os valores de $y$. Quanto ao coeficiente de correlação de Spearman, aumentos positivos da correlação, aumentos no valor de $X$ correspondem a aumentos no valor de $Y$, e para coeficientes negativos ocorre o oposto. Complementa ainda que é possível determinar se as variáveis em estudo são associadas, na população, ou seja, é possível testar a hipótese de que as duas variáveis estão associadas na população, cujos resultados podem ser vistos no quadro 8. Ateste-se que $n\left(n^{2}-1\right)=19.656$, em todos os casos porque depende apenas da quantidade, $n$, de pares. 
Tabela 8: Coeficiente de correlação de postos.

\begin{tabular}{|l|c|c|}
\hline Relação & $6 \sum d_{i}^{2}$ & $\rho$ \\
\hline INT e DTP/RCL & 18.552 & 0,0577 \\
\hline INT $x$ DCL/RCL & 22.278 & $-0,1334$ \\
\hline EBT $x$ DTP/RCL & 21.426 & $-0,0900$ \\
\hline EBT $x$ DCL/RCL & 21.194 & $-0,1291$ \\
\hline
\end{tabular}

Os valores baixos do coeficiente de correlação de posto mostram que não há indícios de que as variáveis estejam correlacionadas. Pelos resultados obtidos e expressos na tabela 8 , pode-se inferir que os indicadores de gestão fiscal DTP/RCL e DCL/RCL não possuem correlação com os índices de transparência dos estados divulgados pelo Ministério Público Federal (INT) e pela Controladoria Geral da União (EBT), ou seja, esses índices não são elementos que explicam o nível de transparência dos entes da federação.

\section{CONSIDERAÇÕES FINAIS}

A gestão pública, para cumprir com a sua função precípua de promover o bem comum, precisa utilizar os recursos disponíveis com eficiência, eficácia, efetividade e economicidade, para que possa prover aos cidadãos as condições necessárias de saúde, educação, segurança, transporte e lazer. Porém, para atingir esse objetivo, não basta apenas uma boa gestão dos recursos, é preciso divulgar como estes têm sido utilizados e possibilitar aos cidadãos uma participação efetiva nesse processo, a fim de que eles possam ter uma maior interação com os gestores e decidirem de forma conjunta esses recursos serão utilizados.

Nesse contexto, para que efetivamente possa ocorrer uma gestão participativa, a transparência é um elemento essencial. Os atos dos gestores públicos, sobretudo no que concerne à destinação dos recursos, precisam ser divulgados e terem acesso e serem compreendidos por todos, cumprindo o que professam a Carta Magna, na Lei de Responsabilidade Fiscal, na Lei da Transparência e na Lei de Acesso à Informação, tendo esse conjunto de dispositivos legais o intuito exigir que os atos dos gestores sejam acompanhados cada vez mais de accountability.

Então, tendo por base essa necessidade de divulgação dos atos dos gestores públicos e a transparência com que estes têm que ser divulgados, o objetivo deste estudo foi verificar se há uma correlação entre indicadores econômicos e os índices nacionais de transparência da Controladoria Geral da União (CGU) e do Ministério Público Federal (MPF), buscando verificar se os indicadores escolhidos (DTP/RCL e $\mathrm{DCL} / \mathrm{RCL}$ ) seriam variáveis explicativas da transparência apresentada pelos estados. Outros estudos também buscaram evidenciar relações entre índices de transparência e indicadores econômicos e sociais, nos quais foram apontadas uma correlação positiva entre alguns dos indicadores escolhidos e índices de transparência, a exemplo do estudo de Santana Júnior (2008) e de Cruz et al. (2009).

Assim, para analisar se havia correlação entre os indicadores (DTP/RCL e DCL/RCL) e os índices de transparência divulgados pela CGU e pelo MPF, o presente estudo procedeu a uma análise de regressão. Para ratificar os elementos evidenciados pela regressão, fez-se um teste de correlação dos coeficientes por ordem Spearman.

A regressão feita entre o Índice Nacional de Transparência (INT-MPF) e os indicadores de gestão fiscal mostrou que o modelo não é significativo, ou seja, que os indicadores DTP/RCL e DCL/RCL não são variáveis 
explicativas para a transparência apresentada pelos estados. Quando regredido o Índice Escala Brasil Transparente (EBT-CGU) e os indicadores de gestão fiscal, também não foi encontrada correlação entre eles, o modelo mostrou-se não significativo e os indicadores DTP/RCL e DCL/RCL não são variáveis explicativas para a transparência apresentada pelos estados.

Também, fez-se uma análise de regressão visando avaliar qual o impacto que as variáveis explicativas teriam sobre a variável dependente e a constatação desses resultados foram corroboradas pelo teste não paramétrico de Coeficientes de Correlação por Ordem Spearman, comparando, duas a duas, os indicadores de transparência com os indicadores fiscais.

Pelo exposto, foi possível concluir que, diferentemente de outros estudos que evidenciam correlação entre indicadores econômicos e índices de transparência, essa pesquisa evidenciou que não há uma relação entre os índices de transparência dos estados divulgados pelo MPF (INT) e pela CGU (EBT) e os indicadores de gestão fiscal selecionados (DTP/RCL e $D C L / R C L)$, não sendo estes variáveis explicativas para a transparência apresentada pelos entes da federação. Como futuras pesquisas sugere-se a utilização de outras variáveis no intuito de identificar se há correlação entre outros indicadores econômicos e sociais e índices de transparência, sejam os utilizados nesse trabalho ou outros índices recomendados pela literatura.

\section{REFERÊNCIAS}

CRESWELL, J. W.. Projeto de pesquisa: métodos qualitativo, quantitativo e misto. 3 ed. Porto Alegre: Artmed, 2010.

CRUZ, C. F.. Transparência da gestão pública municipal: um estudo a partir dos portais eletrônicos dos maiores municípios brasileiros. Revista de Administração Pública, Rio de Janeiro, v.46, n.1, p.153-76, 2012.

CRUZ, C. F.; SILVA, L. M.; SANTOS, R.. Transparência da gestão fiscal: um estudo a partir dos portais eletrônicos dos maiores municípios do estado do Rio de Janeiro. In: ENCONTRO DE ADMINISTRAÇÃO DA INFORMAÇÃO, 2. Anais. Recife: ANPAD, 2009.

FIPECAFI. Disclosure: você sabe o que é?. São Paulo: FIPECAFI, 2012.

GAVELIN, K.; BURALL, S.; WILSON, R.. Open Government: beyond static measures. Paris: OECD, 2009.
GIL, A. C.. Métodos e técnicas de pesquisa social. 6 ed. São Paulo: Atlas, 2008.

NERY, C. R. A.. Indicadores de transparência na administração pública: metodologias de avaliação da transparência e estudo de caso da área de Recursos Humanos do Senado Federal. Monografia (Pós-Graduação em Administração Legislativa) - Instituto Legislativo Brasileiro, Brasília, 2014.

OSBORNE, D.; GAEBLER, T.. Reinventando o Governo. 6 ed. Brasília: MH Comunicação, 1995.

RIBEIRO, C. P. P.; ZUCCOLOTTO, R.. Identificação dos fatores determinantes da transparência na gestão pública dos municípios brasileiros. Brasília: ESAF, 2012.

SCHEFFER, E. I.. Controle Social: Teoria e Prática. Cuiabá: INBRACO, 2007.

A CBPC - Companhia Brasileira de Produção Científica (CNPJ: 11.221.422/0001-03) detém os direitos materiais desta publicação. Os direitos referem-se à publicação do trabalho em qualquer parte do mundo, incluindo os direitos às renovações, expansões e disseminações da contribuição, bem como outros direitos subsidiários. Todos os trabalhos publicados eletronicamente poderão posteriormente ser publicados em coletâneas impressas sob coordenação da Sustenere Publishing, da Companhia Brasileira de Produção Científica e seus parceiros autorizados. Os (as) autores (as) preservam os direitos autorais, mas não têm permissão para a publicação da contribuição em outro meio, impresso ou digital, em português ou em tradução. 